\title{
NOVA MADEIRA DE GIMNOSPERMA DO PERMIANO DO RIO GRANDE DO SUL
}

\author{
MARIA HELENA DOHMS*
}

\begin{abstract}
The fossil specimen described here was found $12 \mathrm{~km}$ south of Bage along the Bage - Aceguá Road, Rio Grande do Sul, Brazil, in the black shales of Valente Facies (Irati Formation Permian) of the Gondwana sequence of the Paraná Basin. The fossil was classified as Bageopitys articulata n. gen., $n$. sp. The well preserved nature of the specimen permitted a precise morfo-anatomic study of the pith and of the primary and secondary xylem. In adition to its own particular charac. teristics the fossil record shows general anatomic traces ("araucarioid" pits to "mixed") which are commonly observed in the great majority of the Gondwana woods.
\end{abstract}

INTRODUÇÃo Apesar de escassamente estudadas até o momento, as madeiras petrificadas por intuscrustação constituem-se num dos melhores, mais importantes e frequientes fósseis vegetais do Paleozóico do Rio Grande do Sul. Ocorrendo não associados a outros organismos, oferecem informações morfotaxonômicas, e conseqüentemente filogenéticas, que vền valorizar estratigraficamente a importância de sua pesquisa.

Desta forma, com o presente trabalho, objetivamos dar início a uma pesquisa sistemática da abundante flora de madeiras fósseis existente neste Estado. Para tanto, dedicamo-nos ao estudo morfológico e taxonômico de um exemplar lenhoso para, no final, chegarmos a interpretações fillogenéticas e bioestratigráficas.

$\mathrm{O}$ presente material provém do Afloramento Valente, situado à margem direita da RS-153 (Bage-Aceguá), de quem se dirige à localidade de Aceguá, localizado aproximadamente $12 \mathrm{~km}$ ao sul do centro da cidade de Bage $\left(31^{\circ} 25^{\prime} 5^{\prime \prime} \mathrm{S}-54^{\circ} 8^{\prime} 9^{\prime}\right.$ :W Greenwich), no município de mesmo nome, Rio Grande do Sul, Brasil.

Encontramos aí ravinas de até $3 \mathrm{~m}$ de profundidade, numa área de aproximadamente $1600 \mathrm{~m}^{2}(160 \mathrm{~m}$ de comprimento $\times 10 \mathrm{~m}$ de largura). O sedimentito deste afloramento é um folhelho cinza-chumbo, finamente laminado, com estrutura concóide, alterando para cores amareladas, cortado por veios verticalizados e preenchidos por sílica, típico da Fácies Valente (Figueiredo Filho, 1972), da Formação Irati no Estado do Rio Grande do Sul. $\mathrm{O}$ afloramento está orientado na direção $\mathrm{E}-\mathrm{-W}$, mergulhando suavemente para o sul. Quantidade considerável de fragmentos de madeiras fósseis de vários tamanhos (de 2 a $30 \mathrm{~cm}$ ) é aí encontrada, tanto na superficie como no interior do sedimento, muito bem preservada por intuscrustação de sílica em sua maioria.

Estudo de um exemplar de madeira fóssil DIAGNOSES O presente exemplar provém do Afloramento Valente, situado à margem da rodovia Bagé-Aceguá, a $12 \mathrm{~km}$ ao sul da cidade de Bagé ( $31^{\circ} 25^{\prime} 5^{\prime \prime} \mathrm{S}-54^{\circ} 8^{\prime} 9^{\prime \prime} \mathrm{W}$ Greenwich), município de Bagé, Rio Grande do Sul, Brasil, onde se encontrava associado aos folhelhos cinza-chumbo da Fácies Valente, Formação Irati (Permiano).

Bageopitys n. gen.

DIAGNOSE

- Traços foliares simples ou duplos em espirais.

- Medula sólida, homogênea, circular, sem bainha parenquimatosa; células pontuadas.

*Departamento de Geociências, Universidade de Brasília, Brasília, Distrito Federal, Brasil 
-Xilema primário mesarco.

-Xilema secundário centrifugo.

- Anéis de crescimento nítidos; canais secretores e espessamentos espiralados ausentes. - Traqueídeos com pontuações radiais alternas, subopostas a opostas, contíguas ou separadas.

- Paredes horizontais das células dos raios lenhosos pontuadas.

- Campos de cruzamento com oculiporos araucarioides.

Bageopitys articulata n. sp. (Figs. 1 a 7, Quadros 1 a 5)

\section{DIAGNOSE}

- Traços foliares simples ou duplos, em espirais destras e sinistras que se cruzam a $90^{\circ}$.

- Medula sólida, homogênea, constituída por células parenquimáticas pontuadas, mais largas que altas.

-Xilema primário mesarco, em pequenos agrupamentos irregulares de células, com traqueídeos escalariformes e reticulados.

-Xilema secundário centrífugo, com anéis de crescimento nítidos e bruscos.

- Presença de meatos entre os traqueídeos, nos quais o diâmetro radial varia de 29 a $36 \mu$ (madeira inicial) e de 11 a $15 \mu$ (madeira final), e o diâmetro tangencial, de 18 a $36 \mu$.

-Pontuações tangenciais ausentes.

-Pontuaçóes radiais de 1-3 seriadas, alternas, subopostas a opostas, contíguas ou separadas; lumens cruzados ou em fenda.

-1-6 pontuações no campo de cruzamento, areoladas, pequenas.

-Raios lenhosos unisseriados, parcialmente bi ou trisseriados, articulados, com 1-25 andares de altura; densidade dos raios: $9-14 / \mathrm{mm}$ tangencial e $35-46 / \mathrm{mm}^{2}$ tangencial.

HOLÓTIPO: Exemplares polidos e lâminas delgadas n..$^{\circ} 742.51$, depositados na Seç̧ão de Paleobotânica do Departamento de Paleontologia e Estratigrafia do Instituto de Geociências da Universidade Federal do Rio Grande do Sul, Porto Alegre, Brasil.

LOCALIDADE: Rodovia Bagé--Aceguá (12 km ao sul de Bagé), município de Bagé, Rio Grande do Sul, Brasil.

HORIZONTE: Formação Irati, Fácies Valente.

IDADE: Permiano.

Morfologia $O$ exemplar aqui estudado apresenta uma forma cilindrica medindo $4,6 \mathrm{~cm}$ de comprimento e cerca de $2 \mathrm{~cm}$ de diâmetro (porção mais alargada, $2,4 \mathrm{~cm}$; e mais estreitada, $1,9 \mathrm{~cm}$ ).

Apresenta em um de seus lados distintas marcas foliares losangulares, simples ou duplas, cuja estrutura não é bem visível. Essas marcas medem aproximadamente $2 \mathrm{~mm}$ de altura e $1 \mathrm{~mm}$ de largura, separando-se lateralmente uma de outra por mais ou menos $4 \mathrm{~mm}$, e verticalmente por $8 \mathrm{~mm}$. Distribuem-se em espirais destras com filotaxia $1 / 24$, e espirais sinistras, com filotaxia $1 / 36$. As espiras se cruzam a $90^{\circ}$.

O espécime mostra b́tima preservação, tendo sido fossilizado por substituição quase completa por sílica microgranular. Pequenas fraturas horizontais foram preenchidas por calcedônia. Os bordos apresentam-se levemente arredondados e fragmentam-se no xilema secundário conforme as linhas limitantes das zonas de crescimento e os raios lenhosos. A coloração do exemplar é marrom-pardacento-claro, alterando para amarelo-palha (como o sedimento onde foi encontrado).

Apenas um exemplar desta madeira foi encontrado até o presente. 

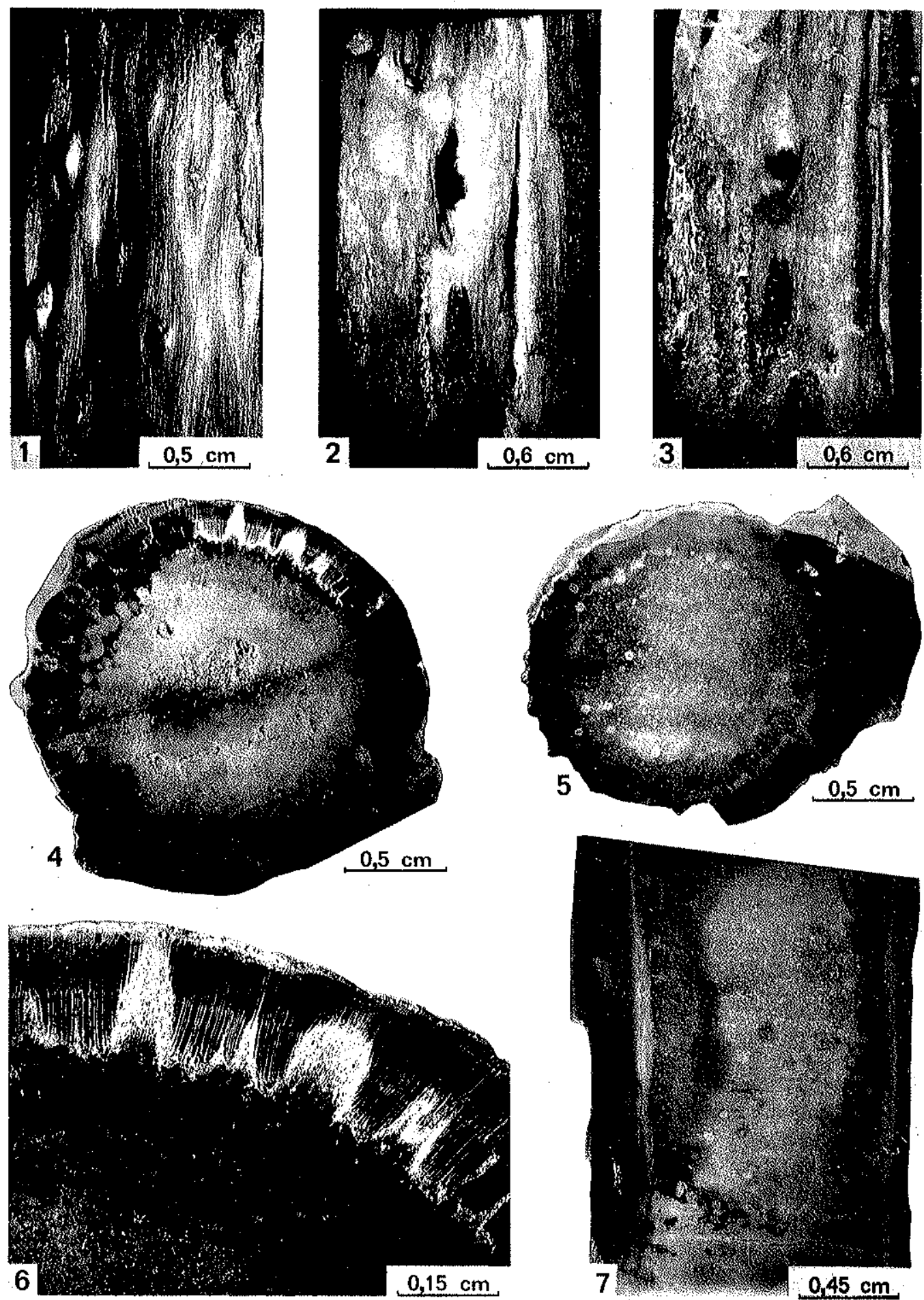

Bageopitys articulata n. gen, n. sp.

Figura 1 - Marcas foliares em disposição espiralada. Figuras 2 e 3 - Detalhes de marcas foliares. Figura 4 - Seção polida transversal. Figura 5 - Corte transversal na extremidade de melhor preservação. Figura 6 - Detalhe da seção polida transversal. Podem-se observar a medula homogênea, xilema com zonas de crescimento e saída de marcas foliares. Figura 7 - Corte radial mostrando lacunas horizontais totais ou parciais 


\section{II}
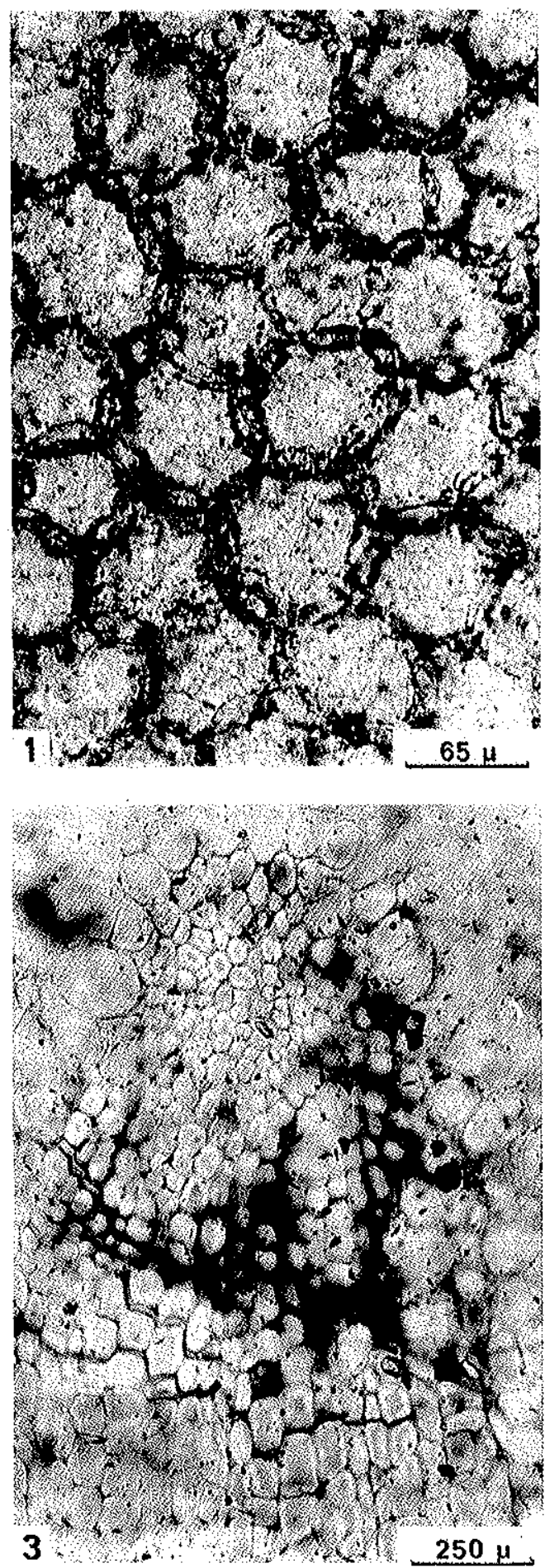
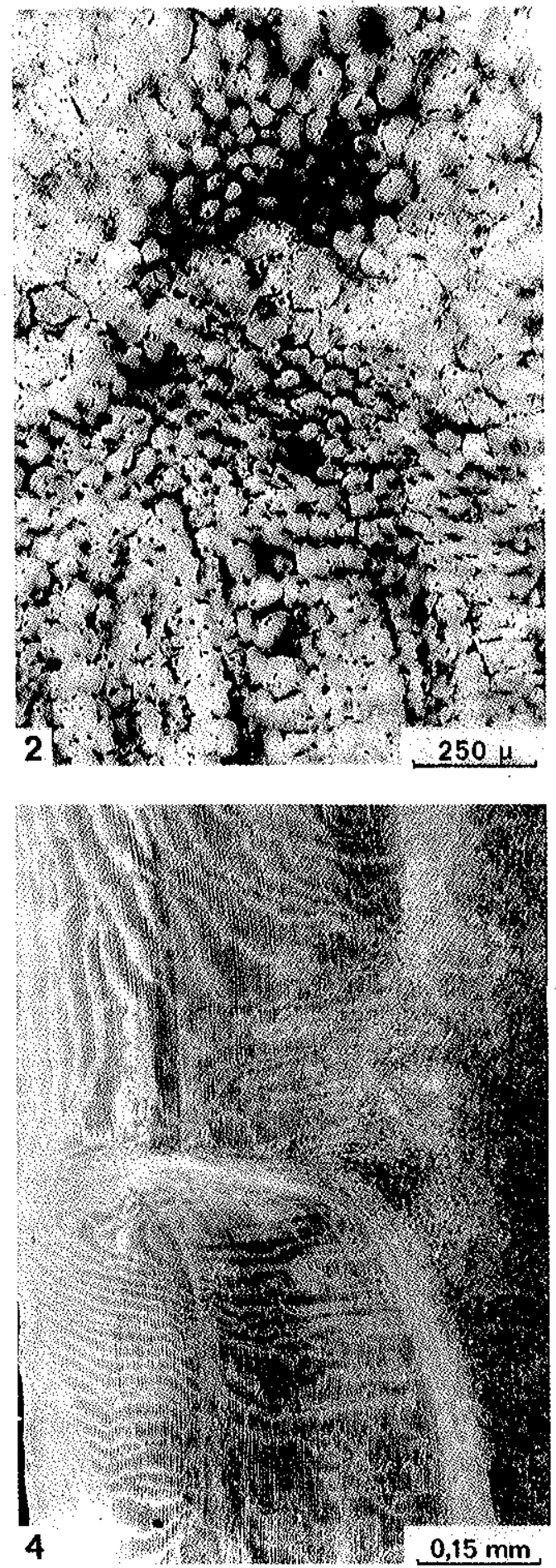

Bageopilys articulata n. gen., n. sp.

Figura 1 - Lâmina delgada transversal. Células parenquimáticas da medula mostrando suas paredes infladas. Figura 2 - Lâmina delgada transversal. Xilema primário mesarco, com protoxilema substituído por células parenquimáticas (?). Figura 3 - Lâmina delgada transversal. Xilema primário mesarco. Figura 4-Seção polida radial. Saída de um traço foliar 

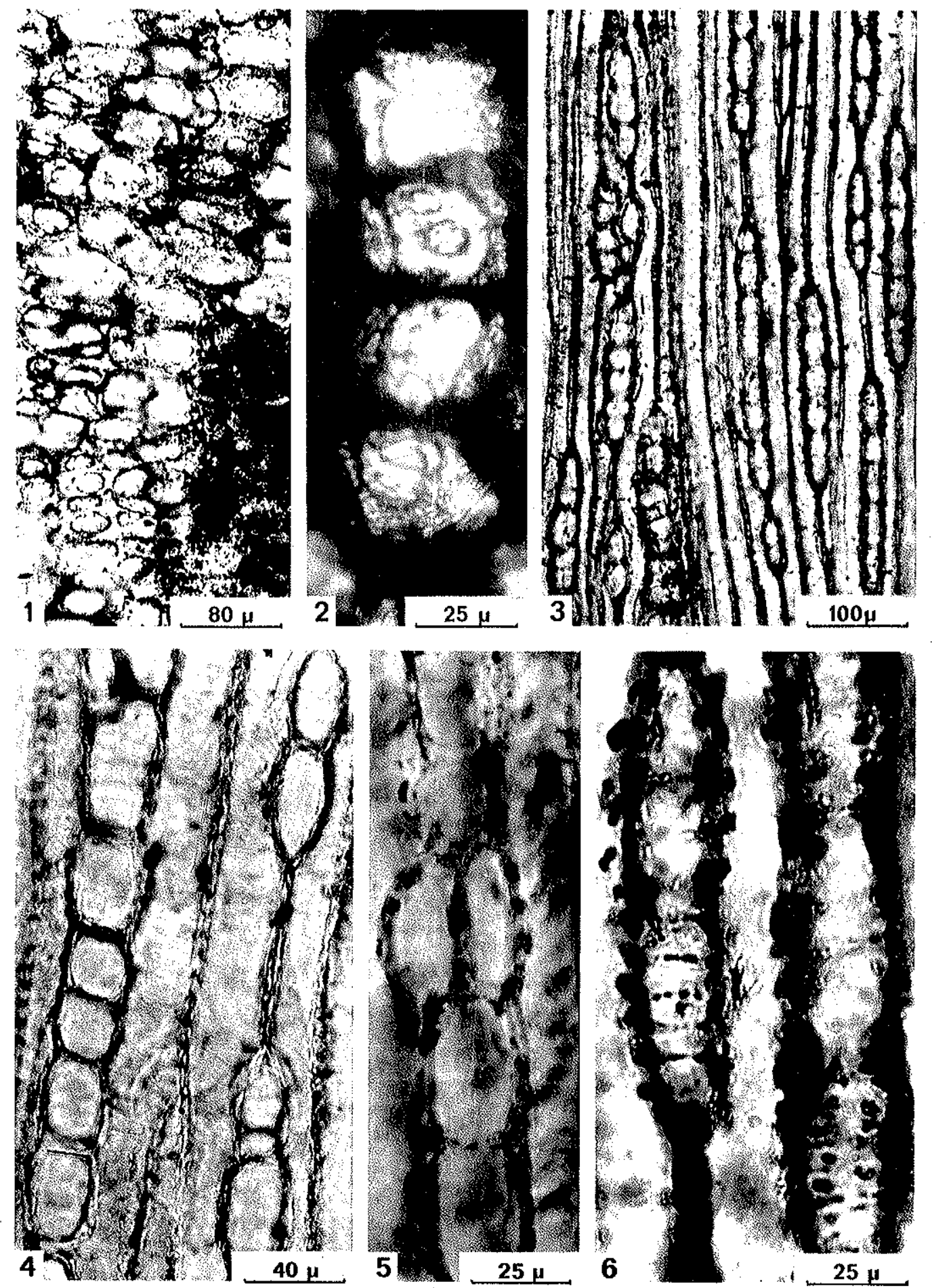

Bageopitys articulata $n$. gen., n. sp.

Figura 1 - Lâmina delgada radial. Células parenquimáticas medulares, com paredes pontuadas. Figura 2 - Lâmina delgada radial. Células parenquimáticas medulares, com paredes pontuadas em detalhe. Figura 3 - Lâmina delgada tangencial. Raios lenhosos unisseriados, articulados ou não. Figura 4 - Lâmina delgada tangencial. Raios lenhosos unisseriados. Pontuações radiais em perfil. Figura 5 - Lamina delgada tangencial. Raios lenhosos unisseriados parcialmente bisseriados. Figura 6 - Lâmina delgada tangencial. Raios lenhosos unisseriados. Pontuações clas paredes celulares horizontais e verticais 

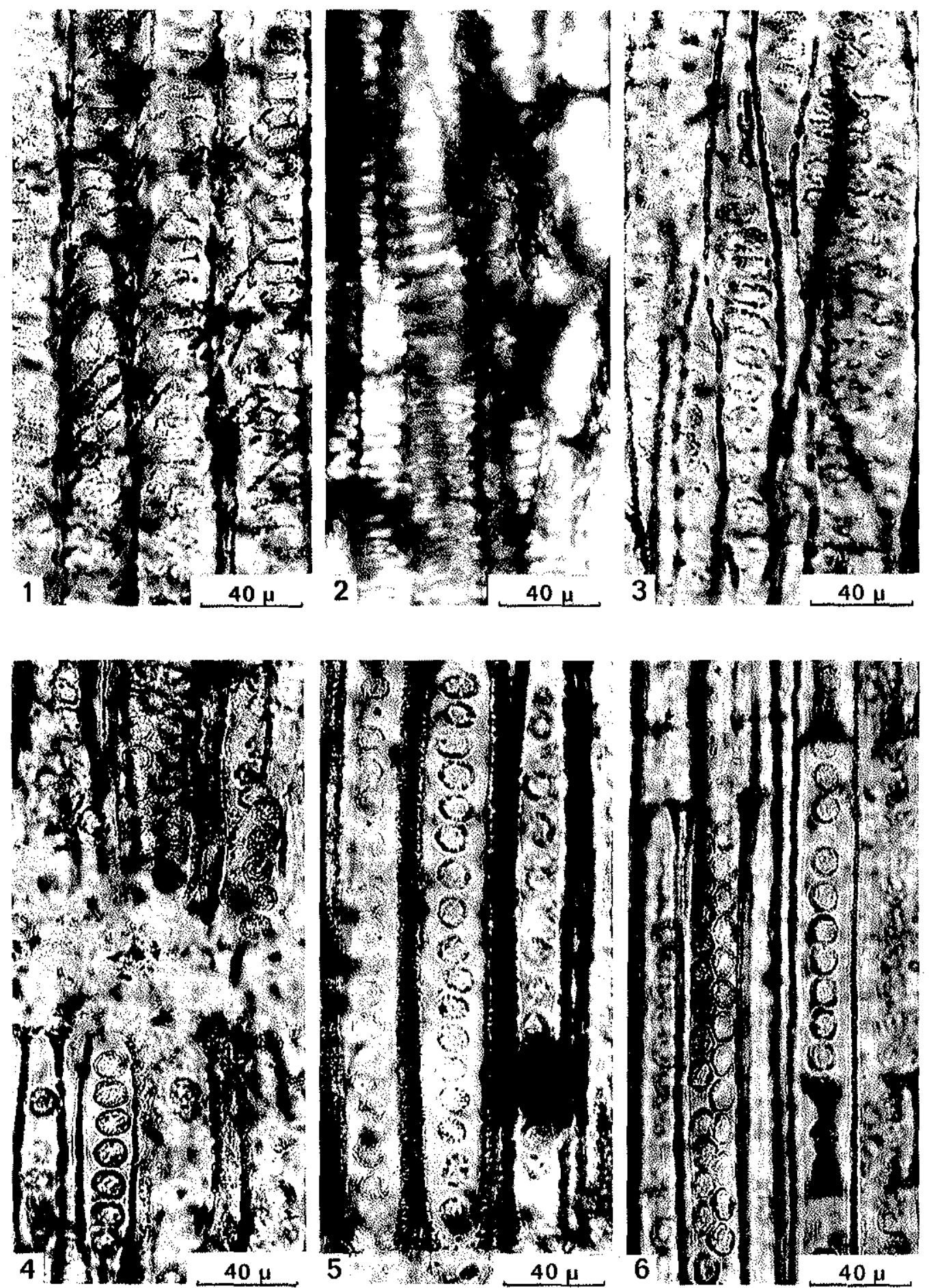

Bageopilys articulala n. gen., n. $s p$.

Lâminas clelgadas radiais

Figuras 1 e 2 - Fibras traqueídeos espiralaclas e escalariformes do xilema primário. Figura 3 Fibras traqueídeos com pontuações areoladas escalariformes e unisseriadas arredondadas. Figuras 4,5 e 6 - Fibras traqueídcos com pontuações unisseriadas, espaçaclas ou contíguas, e bisseriadas, subopostas ou alternas 

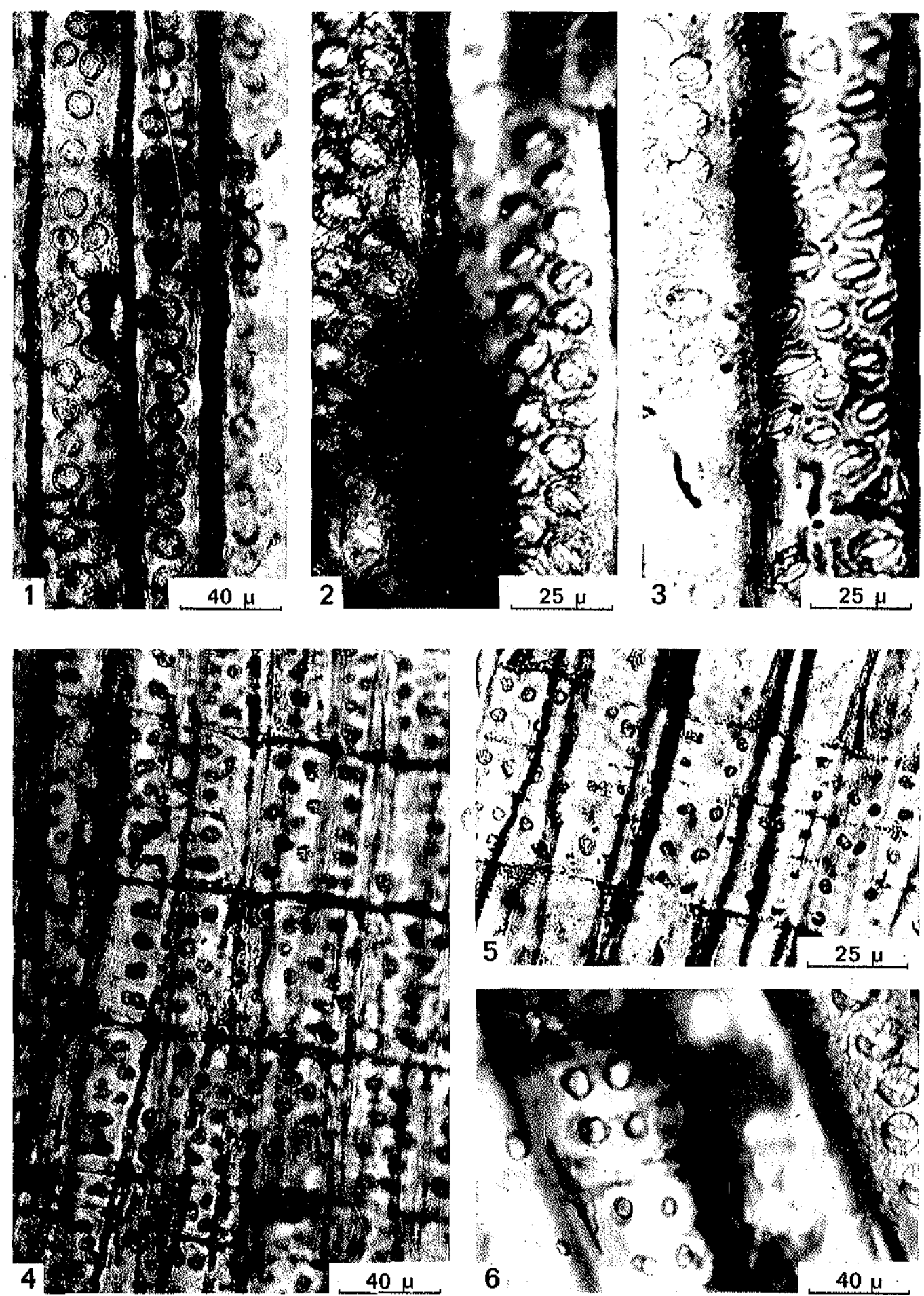

Bageopitys arliculata n. gen., n. sp.

Lâminas delgadas racliais

Figura 1 - Fibras traqueideos com pontuações areoladas unisseriadas achatadas e bisseriadas espaçadlas, opostas, subopostas ou alternas. Figura 2 - Fibras traqueídeos com pontuações areoladas bisseriadas contíguas, subopostas ou alternas, com lúmen cruzado. Figura 3 - Fibras traqueideos com pontuações areoladas trisseriadas alternas. Figuras 4 e 5-Campos de cruzamento com 1-6 pequenos oculiporos. Figura 6 - Detalhe de campos de cruzamento 
Anatomia MEDULA A medula ć circular, central, sólida, com diâmetro de $1,6 \mathrm{~cm}$, estando levemente achatada (por compressão?) e perfazendo $80 \%$ do exemplar.

E constituída apenas por células parenquimáticas arredondadas a poligonais, dispostas irregularmente, sem meatos. As dimensões variam pouco, como, por exemplo (comprimento radial $\times$ largura tangencial): $72 \mu \times 72 \mu ; 54 \mu \times 50 \mu ; 79 \mu \times 61 \mu ; 133 \mu \times$ $\times 122 \mu ; 83 \mu \times 68 \mu$; e as paredes (dupla parede) têm de $13 \mu$ a $23 \mu$ de espessura, algumas atingindo até $27 \mu$. Alterações nas dimensões das células não apresentam maior significado do centro para a periferia da medula. As paredes são infladas e têm 1 ou 2 pontuaç̃̃es simples ovaladas ou circulares, com diâmetros variados: $32 \mu \times 32 \mu ; 64 \mu \times 64 \mu ; 14 \mu \times$ $\times 18 \mu ; 59 \mu \times 68 \mu$.

A medula penetra profundamente no xilema.

Em corte longitudinal, as células se dispõem em fileiras verticais irregulares. São poligonais ou ovaladas, mais largas que altas. Apresentam ângulos pouco arredondados, havendo inexistência de meatos. A largura radial varia de $72 \mu$ a $127 \mu$ e a altura é compreendida entre $23 \mu$ e $64 \mu$. As paredes possuem pontuações simples, únicas e alongadas horizontalmente (diâmetros variando entre $27 \mu \times 32 \mu-27 \mu \times 60 \mu$ ); ou duas circulares lado a lado $(32 \mu \times 37 \mu)$.

Espaços vazios alongados, paralelos entre si e transversais ao eixo longitudinal da medula, ou irregulares e dispersos (poucos) são observados, provavelmente de origem secundária (mecânica).

Formações escuras, globulares estão dispersas na medula (fungo parasita ou atividade bacteriana?).

Os elementos resiníferos e esclerenquimáticos estão ausentes.

FORMAÇOOES PRIMÁRIAS Circundando a medula, pode-se, observar o xilema primário formando cerca de 15 maciços lenhosos, subdivididos em até 5 maciços menores.

Os traqueídeos do protoxilema de posição mesarca são de arredondados a poligonais, com paredes finas ( $2 \mu$ a dupla parede), dispostos irregularmente em corte transversal (Fig. 1). Suas dimensões são pouco variáveis, como, por exemplo (comprimento radial $\times$ $\times$ largura tangencial): $10 \mu \times 12 \mu ; 13 \mu \times 19 \mu ; 17 \mu \times 21 \mu$. Um corte longitudinal permite a observação de traqueídeos espiralados (1-10 células) onde o diâmetro varia de 20 a $30 \mu$. A espessura das paredes radiais e das paredes tangenciais é de $1 \mu$ a $2 \mu$.

Metaxilema centrifugal e centripetal presente, com traqueídeos irregularmente dispostos, arredondados a poligonais, com dimensões maiores que os traqueídeos do protoxilema (comprimento radial $\times$ largura tangencial): $11 \mu \times 7 \mu ; 13 \mu \times 14 \mu ; 18 \mu \times 25 \mu$; $22 \mu \times 25 \mu ; 25 \mu \times 25 \mu$. Suas paredes são mais espessas: 3-6 $\mu$ (dupla parede). Em corte longitudinal, podem-se observar 3-5 elementos do metaxilema centrípeto, anelares, espiralados e escalariformes. No metaxilema centrífugo, as fibras traqueídeos são escalariformes (abundantes) e reticuladas (pouco numerosas). Os diâmetros dos traqueídeos escalariformes variam de $8 \mu$ a $15 \mu$ e dos traqueídeos reticulados, de $16 \mu$ a $25 \mu$. A espessura das paredes tanto radial como tangencial é de $2 \mu$. Alguns traqueídeos do xilema primário possuem terminaçб̃es horizontalizadas, perpendiculares ao seu eixo maior. Por vezes, no centro dos feixes primários pode-se observar ou uma pequena lacuna, que talvez corresponderia aos traqueídeos reabsorvidos, ou células parenquimáticas, que seriam formadas no lugar do protoxilema. Alguns feixes primários nã́o apresentam estrutura mesarca.

MADEIRA SECUNDARIA Lâminas delgadas transversais Mostram fibras traqueídeos alinhadas radialmente e separadas por numerosos raios medulares. É uma madeira homoxilada do tipo picnoxílico. 


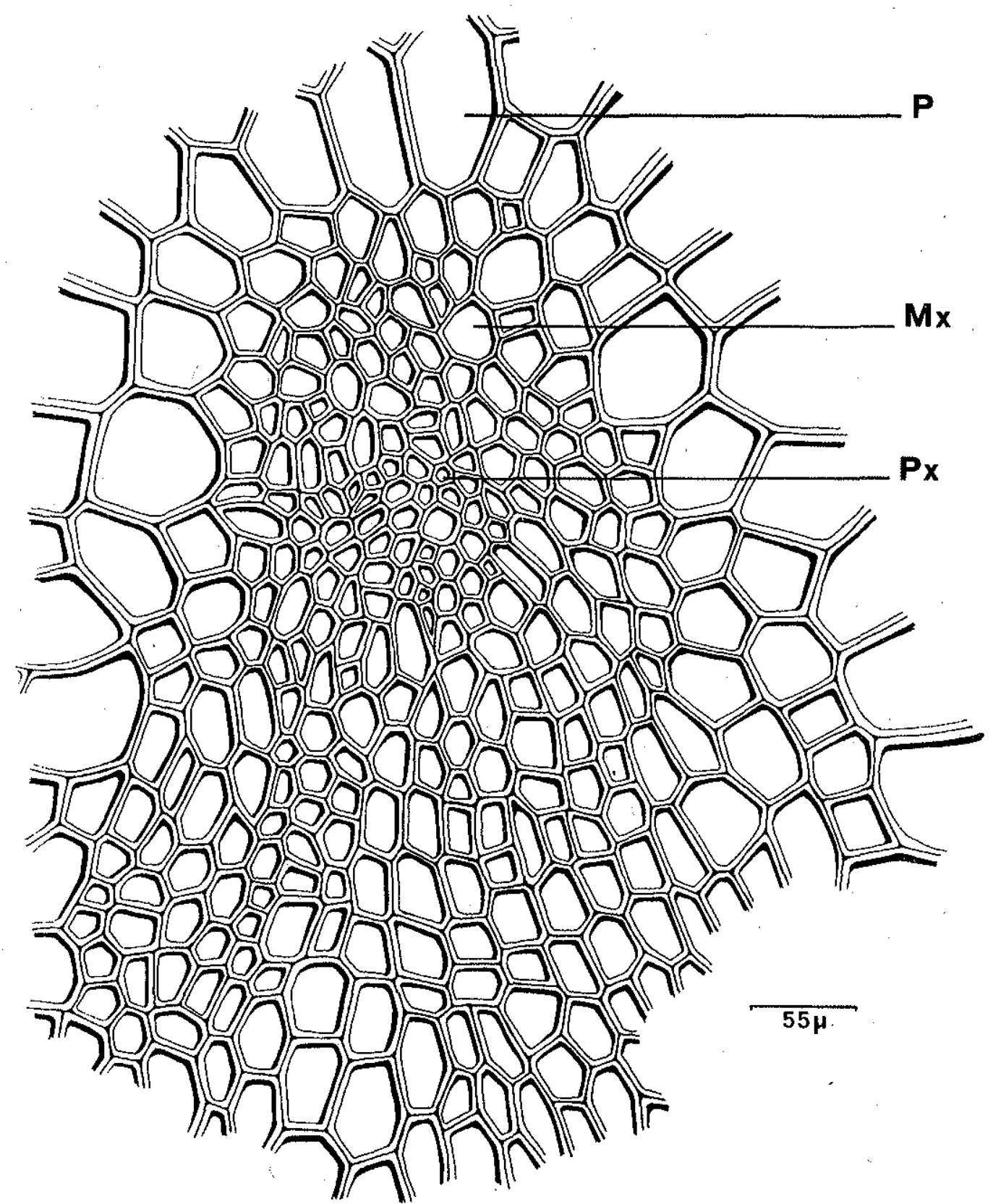

Figura 1 - Bageopitys articulata n. gen. et n. sp. Detalhe da lâmina delgada transversal. Xilema primário centrípeto e centrífugo. P: medula; Px: protoxilema; $\mathbf{M x}$ : metaxilema

As zonas de crescimento são nítidas ao microscópio (Fig. 2). Contam-se 2 numa largura de $4 \mathrm{~mm}$. A madeira final, situada a $1 \mathrm{~mm}$ e a $2 \mathrm{~mm}$ da medula (bordo da medula), se estende sobre uma espessura de 1 a 2 traqueídeos (ou $27 \mu$-30 $\mu$ ).

Os canais secretores normais e traumáticos estão ausentes. 


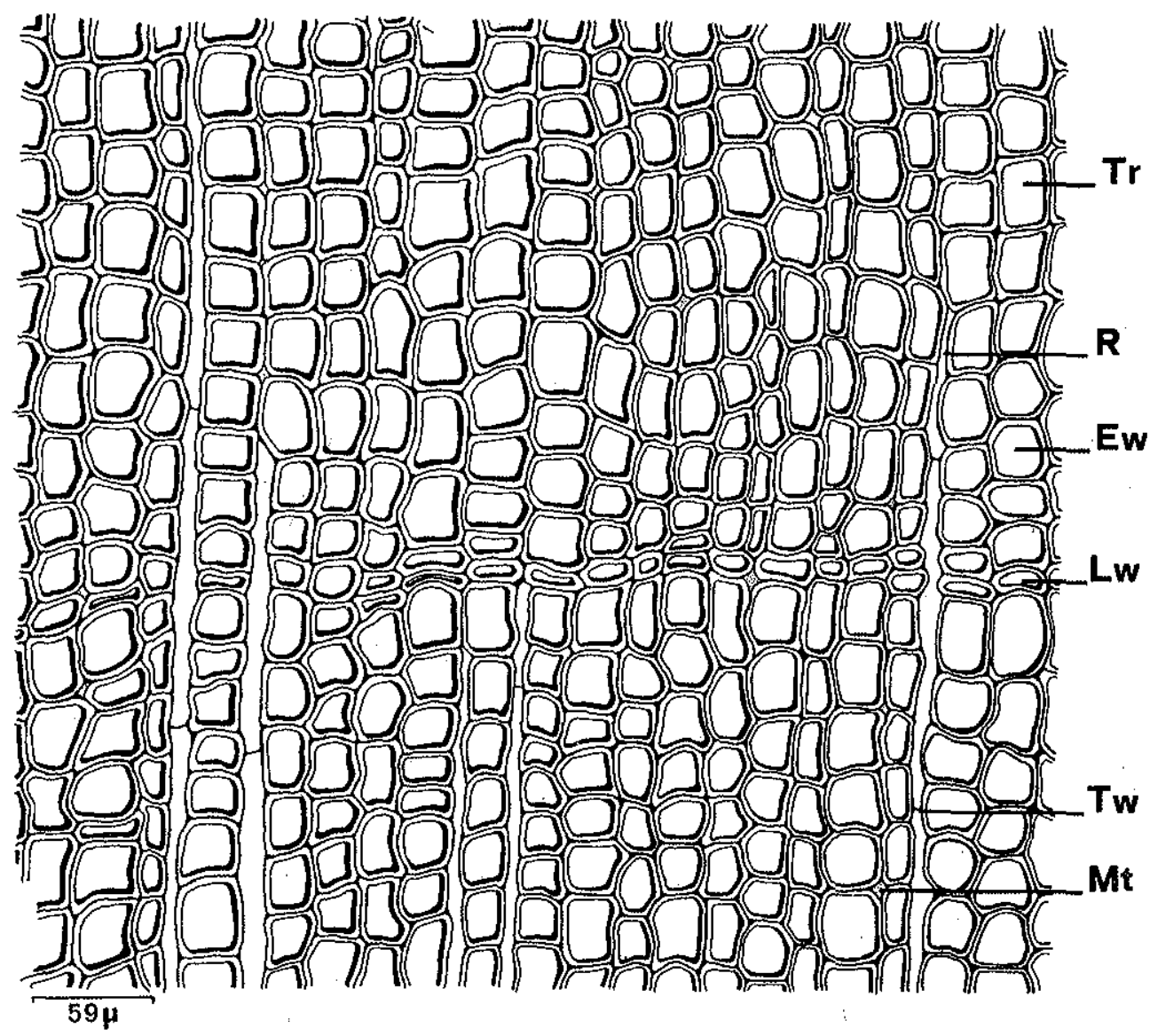

Figura 2 - Bageopitys articulata n. gen. et $n$. sp. Corte transversal mostrando uma estrutura de madeira homoxilada, constituída por fibras traqueídeos $(\mathbf{T r})$ e raios lenhosos $(\mathbf{R})$. Parênquima vertical ausente. Ew: madeira inicial; Lw: madeira final; Tw: parede terminal das células procumbentes; $\mathbf{M t}$ : meatos

Traqueídeos Os primeiros traqueídeos apresentam seus ângulos um pouco arredondados. Suas paredes são pouco espessas: $2 \mu-3,5 \mu$. Assim que se distanciam da medula, as fibras traqueideos da madeira inicial têm um contorno poligonal ou quadrangular, arredondado ou com ângulos agudos, e são por vezes separadas por muitos meatos triangulares ou losangulares pequenos com cerca de $2 \mu-3,5 \mu$ de diâmetro (Fig. 2). As paredes radiais e tangenciais têm sensivelmente a mesma espessura $(3,5 \mu-4,5 \mu)$. A madeira final é constituída por traqueídeos menores e achatados radialmente.

Medidas dos traqueídeos e espessura de suas paredes:

\begin{tabular}{lcccc}
\hline Traqueídeos & $\begin{array}{c}\text { Diâmetro } \\
\text { radial }(\mu)\end{array}$ & $\begin{array}{c}\text { Diâmetro } \\
\text { tangencial }(\mu)\end{array}$ & $\begin{array}{c}\text { Paredes } \\
\text { tangenciais }(\mu)\end{array}$ & $\begin{array}{c}\text { Paredes } \\
\text { radiais }(\mu)\end{array}$ \\
Iniciais & $29-36$ & $18-36$ & $3,5-4,5$ & $3,5-4,5$ \\
\hline Finais & $11-15$ & $18-32$ & $3,5-4,5$ & $3,5-4,5$ \\
\hline
\end{tabular}


Raios lenhosos Células dos raios, dispostas em filas unisseriadas, estão em continuidade com o parênquima medular ou não (quando surgem na porção xilemática primária), porém de forma mais alongada. Medem $60 \mu$-140 $\mu$ de comprimento e $5 \mu-12 \mu$ de largura. As paredes terminais são lisas, pouco oblíquas e atingem $2 \mu$ de espessura. Os raios lenhosos separam-se por 1 a 11 fileiras de fibras traqueídeos (mediana: 2-5) (Fig. 2).

\begin{tabular}{lrrrrrrrrrrr}
\hline $\begin{array}{c}\text { Número de traqueídeos } \\
\text { entre os raios }\end{array}$ & 1 & 2 & 3 & 4 & 5 & 6 & 7 & 8 & 9 & 10 & 11 \\
\hline Freqüência & 10 & 22 & 19 & 19 & 18 & 6 & 2 & 1 & 2 & - & 1 \\
\hline
\end{tabular}

A densidade dos raios é de 9-13 raios por mm horizontal.

Lâminas delgadas tangenciais Traqueídeos Apresentam terminações afiladas e não possuem septos na madeira estabilizada. Porém podem-se observar terminações quase perpendiculares ao nível do lenho primário. Seu comprimento varia de $0,7 \mathrm{~mm}$ a $1,5 \mathrm{~mm}$. Pontuações tangenciais são ausentes.

Raios lenhosos Os raios lenhosos, dispostos irregularmente entre os traqueídeos, são unisseriados $(64,7 \%)$, unisseriados localmente bisseriados $(31,3 \%$ ) ou unisseriados localmente trisseriados ( $4 \%$ (Fig. 3). Os dois últimos casos são dados pela articulação de dois ou mais raios lenhosos unisseriados, fenômeno este que parece ser mais freqüente próximo à medula. Uma observação atenta nos revelou uma modificação na estrutura dos raios. Entretanto a madeira só foi preservada na espessura de $6 \mathrm{~mm}$, tornando muito dificil seguir a evolução desses elementos da medula até o córtex. São constituídos por células procambentes, de seção geralmente circular ou elíptica, cuja altura varia de 14,5 a $46,5 \mu$ e a largura de 14,5 a $32,5 \mu$. As células das extremidades são triangulares a elípticas. As paredes horizontais dos raios são pontuadas. Próximo da medula os raios são baixos. Têm 2-4 células em média, mas sua altura pode variar de 1 a 25 células até a periferia. Uma contagem efetuada a $0,5 \mathrm{~mm}$ da medula sobre 300 raios lenhosos forneceu o seguinte resultado (Fig. 4):

\begin{tabular}{lrrrrrrrrrrrrr}
\hline Número de células & 1 & 2 & 3 & 4 & 5 & 6 & 7 & 8 & 9 & 10 & 11 & 12 & 13 \\
\hline Número de raios & 17 & 44 & 42 & 41 & 25 & 25 & 25 & 14 & 10 & 10 & 7 & 5 & 5 \\
\hline \hline Número de células & 14 & 15 & 16 & 17 & 18 & 19 & 20 & 21 & 22 & 23 & 24 & 25 \\
\hline Número de raios & 5 & 5 & 4 & 4 & 0 & 2 & 4 & 3 & 2 & 0 & 0 & 1 \\
\hline
\end{tabular}

O número de raios por $\mathrm{mm}$ tangencial é de 9.14 e a densidade de raios por $\mathrm{mm}^{2}$ tangencial é de $35-46$ raios.

Parênquima vertical e canais secretores são ausentes.

Lâminas delgadas radiais Traqueídeos Os elementos da madeira secundária são fibras traqueídeos cobertas por pontuações em filas unisseriadas, bisseriadas, mais raramente trisseriadas. São pontuações areoladas achatadas (coeficiente de achatamento $\Sigma=0,5 \sim 0,8$ ) ou circulares $(\Sigma=1$ ), com lúmen cruzado ou em fenda oblíqua.

Numa mesma fibra traqueídeo, e é o caso mais freqüente, podem-se observar pontuações unisseriadas contíguas passando progressivamente a unisseriadas espaçadas ou bisseriadas espaçadas. As pontuações bisseriadas contíguas podem ser alternas, subopostas até opostas. As trisseriadas, mais raras, são alternas e contíguas (Figs. 5 e 6). 


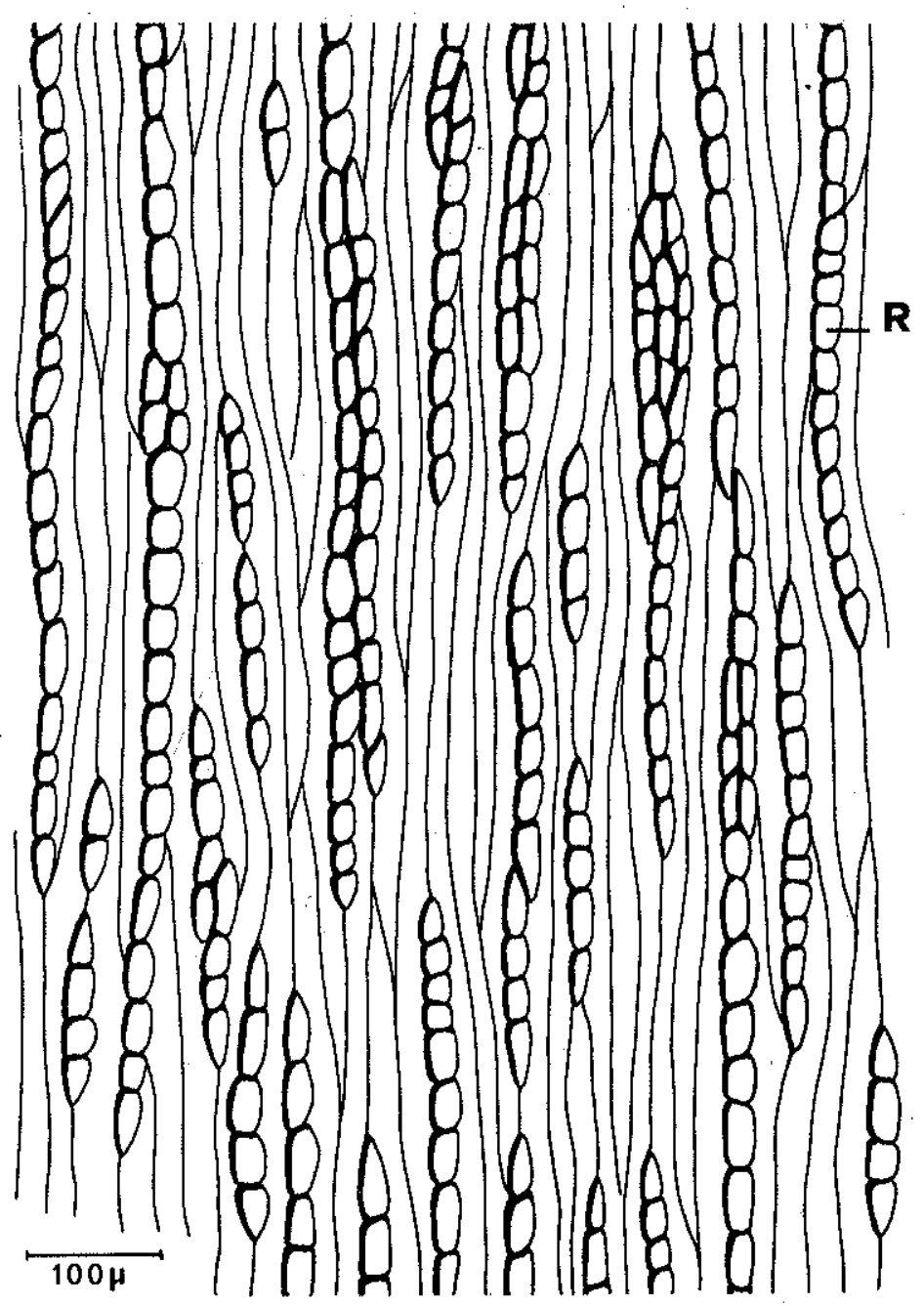

Figura 3 - Bageopitys articulata n. gen. et n. sp. Porção da lâmina delgada tangencial mostrando os raios lenhosos (R) unisseriados, parcialmente bisseriados e trisseriados

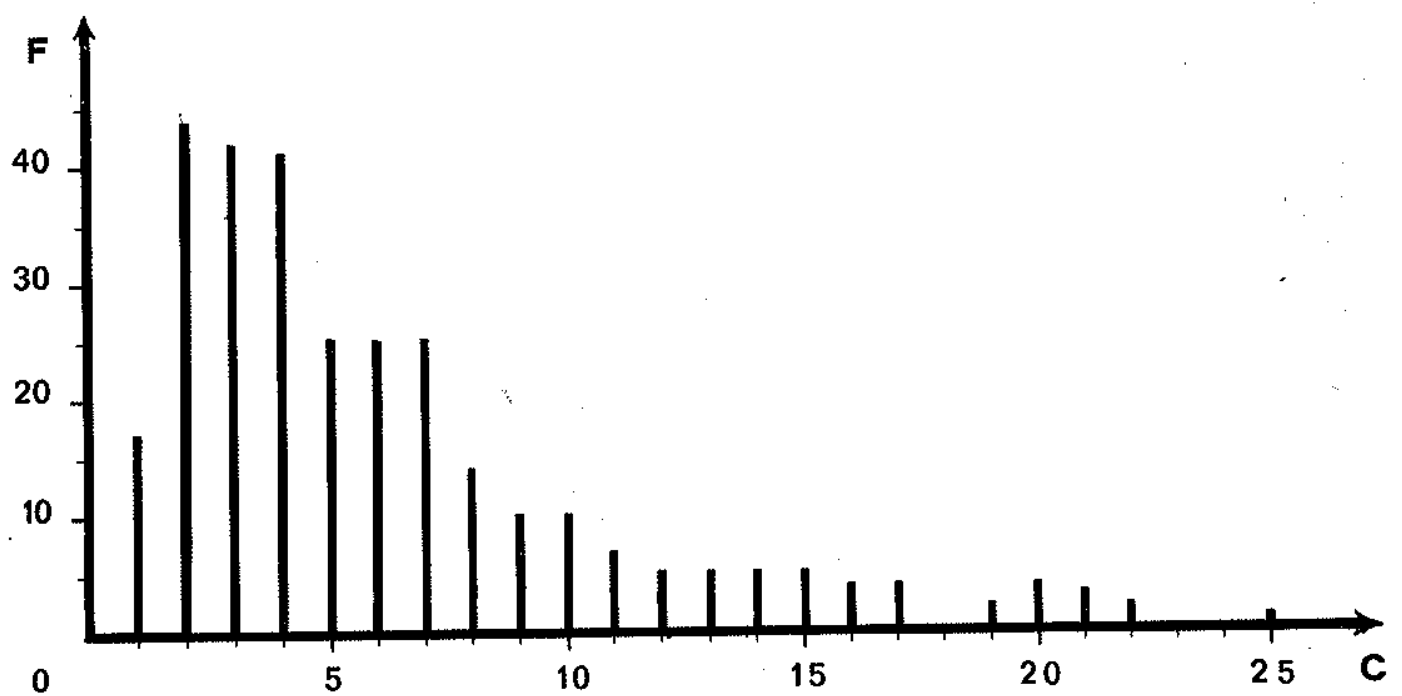

Figura 4 - Bageopilys artzculata n. gen. et n. sp. Histograma mostrando a distribuição cla altura dos raios lenhosos, F: \% de raios; $\mathbf{C}$ : células 


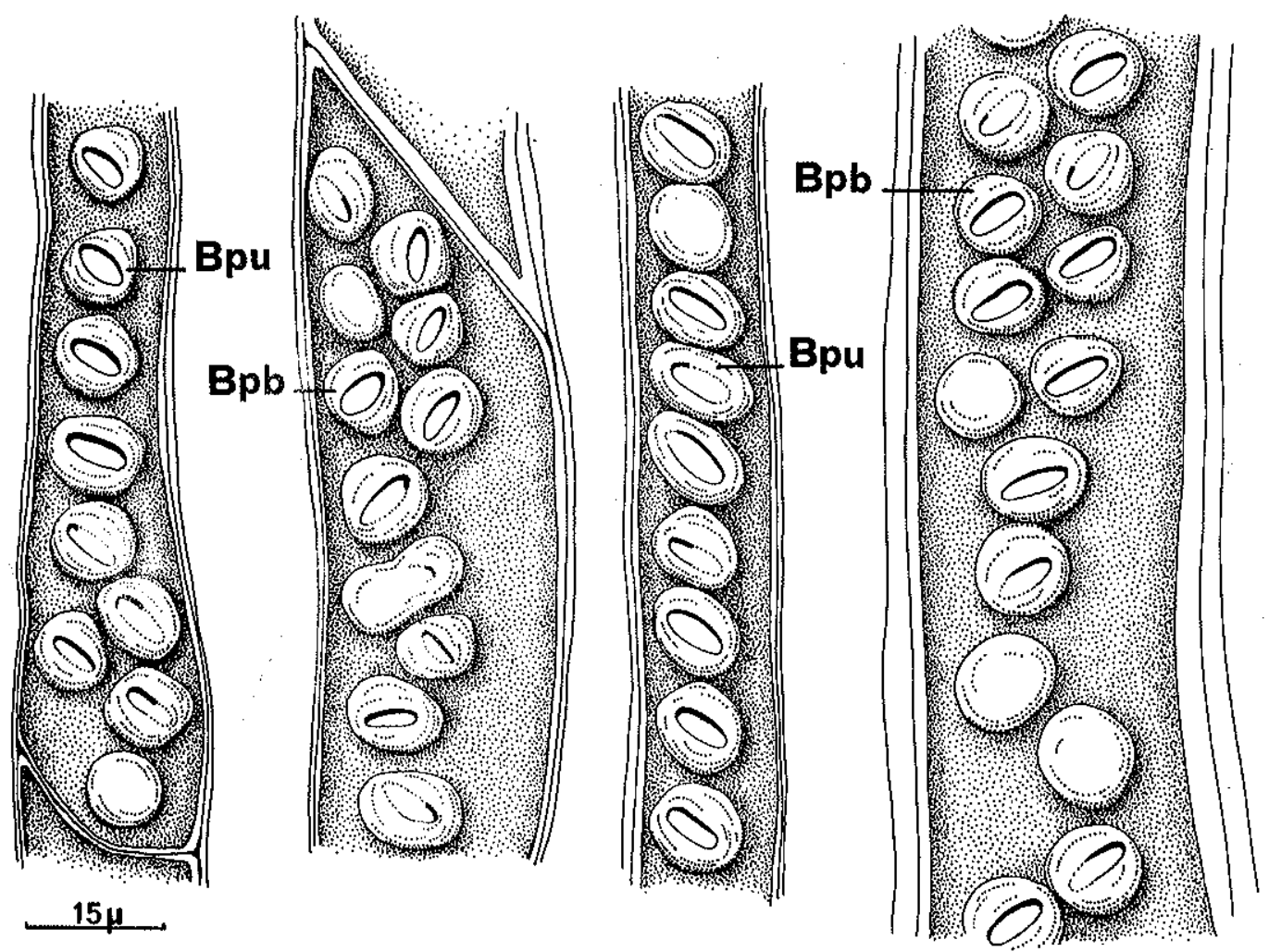

Figura 5 - Bageopitys articulata n. gen. et $n$. sp. Detalhe da lâmina delgada radial. Sobre as paredes das fibras traqueídeos verticais podemos observar pontuações unisseriadas (Bpu), contíguas ou espaçadas, pontuações bisseriadas (Bpb), alternas ou subopostas. São mais ou menos achatadas e não ocupam toda a largura do traqueícleo
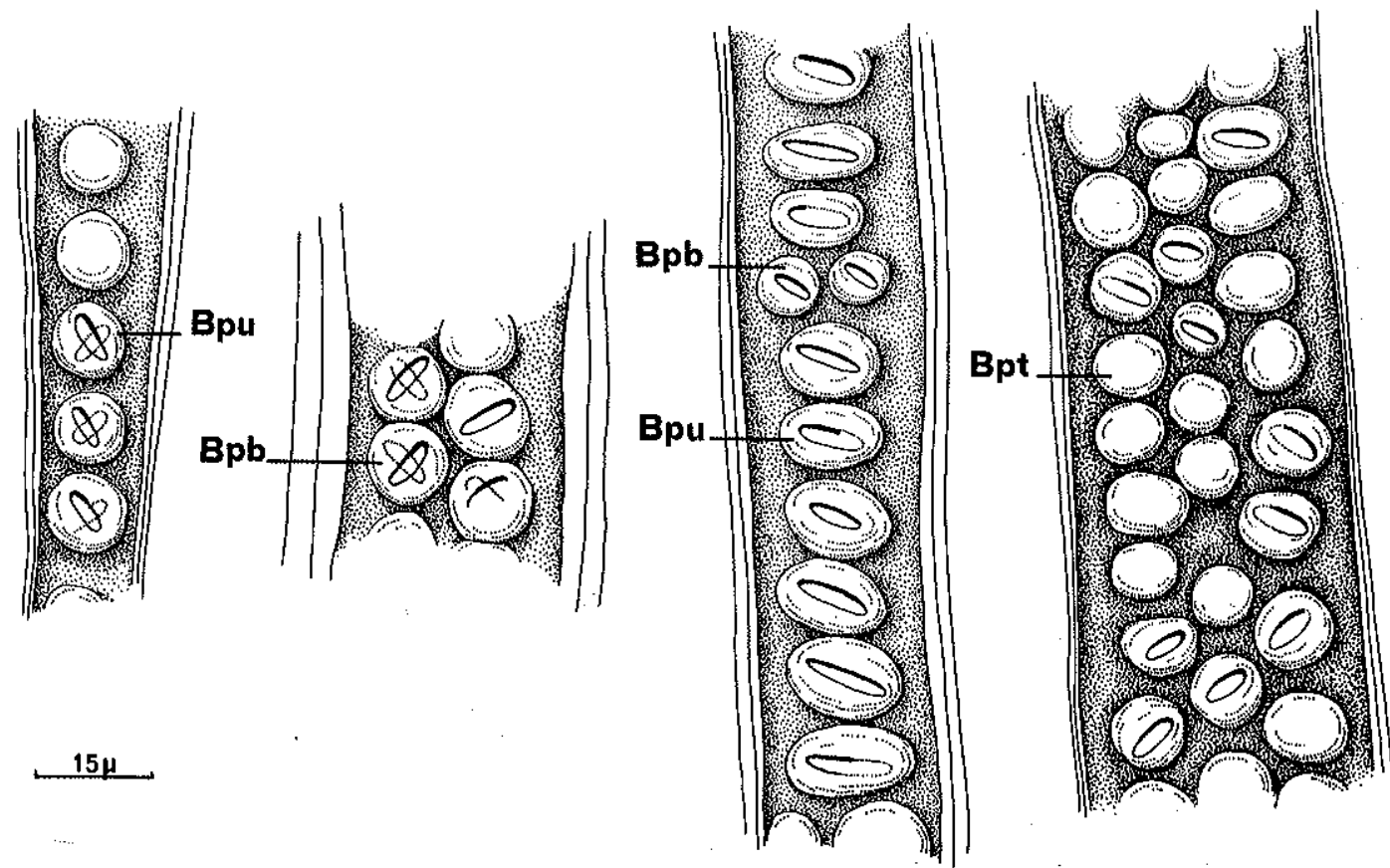

Figura 6 - Bageopitys articulata gen. et sp. nov. Detalhe da lâmina radial. Sobre as paredes dos traqueídeos observamos pontuações unisseriadas (Bpu), espaçadas ou contíguas; bisseriadas (Bpb), alternas ou opostas; trisseriadas (Bpt) alternadas 
É difícil fornecer porcentagens dos diversos tipos de pontuações, pois são encontradas formas diferentes e intermediárias num mesmo traqueídeo. Em geral as pontuações não ocupam toda a largura dos traqueídeos (exceção à maioria das pontuações trisseriadas).

A tabela seguinte dá as medidas dos traqueídeos e suas pontuações radiais.

\begin{tabular}{ccccccccc}
\hline $\begin{array}{c}\text { Pontuações } \\
\text { radiais }\end{array}$ & $\begin{array}{c}\text { Largura dos } \\
\text { traqueídeos }(\mu)\end{array}$ & $\begin{array}{c}\text { Margem } \\
(\mu)\end{array}$ & $\begin{array}{c}\text { Altura } \\
(\mu)\end{array}$ & $\begin{array}{c}\text { Largura } \\
(\mu)\end{array}$ & $\Sigma=\frac{\mathrm{h}}{\mathrm{l}}$ & $\begin{array}{c}\text { Altura do } \\
\text { lumen }(\mu)\end{array}$ & $\begin{array}{c}\text { Largura do } \\
\text { lúmen }(\mu)\end{array}$ \\
\hline $\begin{array}{c}\text { Unisseriadas } \\
\text { contíguas }\end{array}$ & $15-30$ & $1-7$ & $7-9$ & $9-15$ & $0,5-1$ & $1,5-3$ & $5-10$ \\
\hline $\begin{array}{c}\text { Unisseriadas } \\
\text { não-contíguas }\end{array}$ & $13-32$ & $3-11$ & $7-11$ & $7-11$ & $0,5-1$ & $1,5-3$ & $4-8$ \\
\hline $\begin{array}{c}\text { Bisseriadas } \\
\text { contíguas }\end{array}$ & $24-36$ & $0-7$ & $7-11$ & $7-12$ & $0,6-1,2$ & $1,5-3$ & $5-9$ \\
\hline $\begin{array}{c}\text { Bisseriadas } \\
\text { não-contiguas }\end{array}$ & $25-40$ & $1-4$ & $7-11$ & $7-11$ & $0,8-1,2$ & $1,5-3$ & $7-9$ \\
\hline $\begin{array}{c}\text { Trisseriadas } \\
\text { contíguas }\end{array}$ & $29-40$ & $0-4$ & $7-11$ & $7-13$ & $0,8-1,2$ & $1,5-3$ & $6-9$ \\
\hline
\end{tabular}

Raios lenhosos São constituídos unicamente por células procumbentes, onde o comprimento varia de $60 \mu$ a $135 \mu$ e a altura de $20 \mu$ a $45 \mu$. A espessura das paredes duplas atinge $3 \mu$. As paredes terminais são lisas, verticais, às vezes um pouco oblíquas. Igualmente lisas e finas são as paredes horizontais e verticais. Certas células dos raios lenhosos contêm glóbulos de resina.

Campos de cruzamento As pontuaçð̃es do canıpo de cruzamento são do tipo oculiporos, pequenas $(1 \times \mathrm{h}: 3,5 \mu-6 \mu \times 3 \mu-6 \mu)$, ovaladas, por vezes circulares, com lúmen elíptico, oblíquo. Seu número varia de 1 a 6 pontuações por campo, dispersas em grupos ou em duas ou três fileiras horizontais (Fig. 7). Uma contagem em 100 campos de cruzamento forneceu o seguinte quadro de freqüência:

\begin{tabular}{lrrrrrr}
\hline Número de pontuações por campo & 1 & 2 & 3 & 4 & 5 & 6 \\
\hline Frequência em campos de cruzamento & 16 & 32 & 23 & 22 & 3 & 4 \\
\hline
\end{tabular}

As aréolas comumente se encontram mal preservadas, com $2 \mu$ a $3 \mu$ de espessura.

Afinidades COMPARAÇÃO COM OUTRAS MADEIRAS FÓSSEIS A madeira de Bageopitys articulata gen. et sp. nov. é caracterizada pelo xilema primário mesarco, por, uma medula grande e homogênea, e por traqueídeos verticais guarnecidos de pontuaçðes do tipo "araucarióide" a "misto". Canais verticais medulares e parênquima lenhoso vertical são ausentes. Estes caracteres têm sido reconhecidos nas espécies gondwânicas Abietopitys perforata Kraüsel, 1928, Phyllocladopitys capensis Kraüsel, 1928, e Taxopitys africana Kraüsel, 1928.

Abietopitys perforata Kraüsel, 1928. Camadas Ecca?, Permiano, África do Sul. É caracterizada por finos espessamentos isolados nas paredes horizontais e tangenciais das células dos raios lenhosos que lembra o "tipo abietóide"; os raios lenhosos são unisseriados com 1-5 células de altura (raramente mais) e as células parenquimáticas da medula possuem paredes finas e não pontuadas.

Phyllocladopitys capensis Kraüsel, 1928. Camadas Ecca?, Permiano, África do Sul. Apresenta umạ, raramente duas, grandes pontuações arredondadas ou ovaladas por campo 


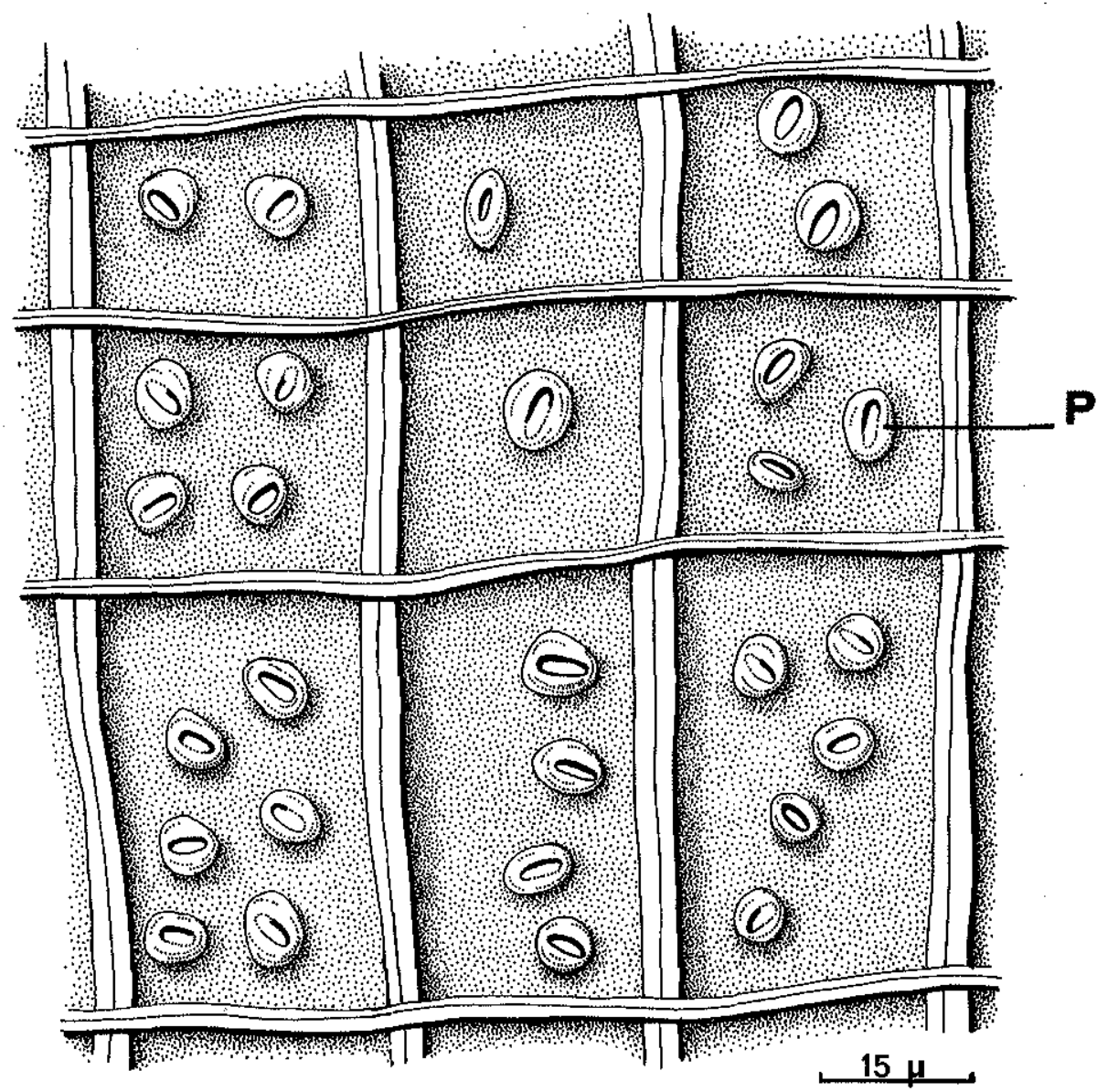

Figura 7 - Bageopitys articulata n. gen. et $n$. sp. Campos de cruzamento. As pontuaçð̃es de campo (P) são areoladas, agrupadas ou em duas ou três fileiras. De um a quatro, raramente cinco ou seis, oculiporos por campo

de cruzamento; os raios lenhosos são unisseriados com 1-18 células de altura; as células medulares parenquimáticas têm paredes finas e grandes espaços intercelulares; e o xilema primário centripetal é em partes isolado da madeira secundária.

Taxopitys africana Kraüsel, 1928. Beaufort?, Permiano, África do Sul. Possui finós espessamentos espiralados nas paredes dos traqueídeos e de 1-2 (até 8) pequenas pontuações em duas ou três fileiras por campo de cruzamento; raios lenhosos unisseriados, raramente bisseriados, apresentam 1-18 células de altura. A medula é parenquimatosa.

Do Hemisfério Norte três gêneros com medula homogênea e caracterizados por um xilema primário mesarco e um xilema secundário sem parênquima lenhoso poderiam ser comparados ao nosso espécime: Mesoxylon Scott e Maslen, 1910, Mesoxylopsis Scott, 1919, e Mesoxyloides Maslen, 1930. Entretanto, os três gêneros descobertos no Carbonífero Superior da Inglaterra têm madeira secundária de Cordaites (fibras traqueídeos verticais com pontuações multisseriadas do tipo araucarióide) e uma medula discóide.

As ilustrações de espécies gondwânicas nơs permitiu reconhecer este caráter em Prototaxoxylon brasilianum Kraüsel e Dolianiti, $1958^{\circ}$ (cf. est. 24, Fig. 50), Dadoxylon (Arauca- 
rioxylon) butiense Rau, 1935 (cf. est. II, Fig. 3), e em Trigonomyelon pedroi (Zeiller) Walton, 1925 (cf. fig. 16, p. 624). A fotografia que representa o corte tangencial de Dadoxylon (Araucarioxylon) butiense é extremamente semelhante ao nosso plano lenhoso tangencial.

Sobre a face externa de nosso exemplar observam-se traços foliares simples, por vezes duplos, distribuídos segundo várias espirais destras e sinistras. Os cortes transversais e longitudinais mostram um feixe de xilema formado por traqueídeos anelados, espiralados e raramente escalariformes, rodeados por algumas células parenquimáticas. Os traços são emitidos segundo um trajeto sensivelmente horizontal, tornando-se mais oblíquo em direção à periferia do xilema secundário. Assim, os planos lenhosos habitualmente observados cortam as marcas foliares obliquamente. $O$ trajeto dos raios lenhosos é perturbado ao nível da emissão das folhas.

Traços foliares duplos são assinalados em certas Pteridospermáceas (Lyginopteris), nas Cordaitales, nas Cycadales e em Ginkgo. Ao contrário, no gênero Mesoxylon (Cordaitales) as emissões foliares são simples, tornando-se duplas após um percurso mais ou menos longo. É dificil, senão impossível, observar se o xilema primário das marcas foliares é centrípeto (Cycadales e Cordaitales Poroxiláceas) ou centrífugo (Cordaitales Cordaitáceas e grupos mais evoluídos) ou ainda centrípeto e centrífugo (Cordaitales Mesoxiláceas).

Podemos igualmente comparar o xilema secundário de nossa madeira com certos planos lenhosos fósseis do Gondwana brasileiro.

Araucarioxylon nummularium (D. White) Maheshwari, 1972. Formação Estrada Nova, Permiano, Rio Grande do Sul, Brasil. Caracteriza-se por zonas de crescimento ausentes; pontuações areoladas unisseriadas, raramente bisseriadas, algumas vezes contíguas e lúmen pequeno e arredondado; nos campos de cruzamento, 1-4 pontuações pequenas e arredondadas, em duas fileiras; raios lenhosos unisseriados, às vezes bisseriados (em 1-3 células) com até 30 células de altura.

Araucarioxylon roxoi (Maniero) Maheshwari e Lepekhina, 1972. Formação Estrada Nova, Permiano, Guareí, São Paulo, Brasil. Distingue-se por zonas de crescimento nítidas e largas; pontuações tangenciais abundantes, redondas ou ovaladas e por raios lenhosos unisseriados, por vezes bisseriados (em 1-4 células), com até 22 células de altura.

Dadoxylon duartei Japiassu, 1970. Formação Morro Pelado, Permiano Superior, Lajes, Santa Catarina, Brasil. Caracteriza-se por pontuações areoladas unisseriadas, bisseriadas e trisseriadas, contíguas ou espaçadas, com lúmen circular a elíptico (tipo "misto" predominante); 4-6 pontuações pequenas em grupos nos campos de cruzamentos; raios lenhosos unisseriados, raramente bisseriados, com até 20 células de altura.

Woodworthia sp. Maniero, 1948. Formação Estrada Nova, Permiano, Rio Claro, São Paulo, Brasil. Apresenta zonas de crescimento ausentes; algumas pontuações tangenciais; campo de cruzamento com fendas inclinadas; raios lenhosos unisseriados com até 25 células de altura; cicatrizes foliares (?) dispersas.

Os exemplares apresentando espirais ao nível das fibras traqueídeos (Prototaxoxylon brasilianum Kraüsel e Dolianiti, 1958), as espécies tipicamente araucarióides (Araucarioxylon manieroi (Kraüsel e Dolianiti) Maheshwari, 1972, e Araucarioxylon meridionale (D. White) Maheshwari, 1972), e as madeiras pouco ou mal descritas (Cedroxylon canoense Rau, 1933, e Dadoxylon derbyi Oliveira, 1936) foram eliminadas desta comparação.

A espécie Dadoxylon (Araucarioxylon) butiense Rau, 1935, foi definida após o estudo de diversos fragmentos de madeira, um dos quais com medula homogênea e raios articulados semelhantes aos do nosso exemplar, e os outros representados apenas por xilema secundário. Infelizmente a descrição incompleta e as medidas muito dispersas não nos permitem comparar esta espécie com a madeira fóssil de Bagé.

A comparação de nossa madeira, encontrada na Formação Irati do Rio Grande do 
Sul, com as espécies gondwânicas e as do Hemisfério Norte evidencia sua estrutura original. Deste modo, propomos o nome de Bageopitys $n$. gen. para a madeira descoberta próximo a Bagé e caracterizada por um xilema primário mesarco. A denominação da espécie $B$. articulata n. sp. foi dada pela presença de raios lenhosos articulados.

VALOR TAXONÔMICO DOS PRINGIPAIS CARACTERES DA MADEIRA FÓSSIL As pontuações nas fibras traqueídeos de Bageopitys articulata gen. et sp. nov. são de diversos tipos. Podemos observar pontuações unisseriadas, bisseriadas e trisseriadas do tipo araucarióicle, com lúmen em fenda oblíqua, na maioria das vezes cruzado (92\%). Paralelamente a este tipo, podemos reconhecer a presença de pontuações arredondadas espaçadas, com lúmen oblíquo $(8 \%)$, muito semelhantes às que são observadas no grupo das Protopináceas do Mesozóico (Jurássico e Cretáceo).

L. Grambast (1960), estudando um Dadoxylon africano pertencente à flora gondwânica, constatou a presença de pontuações do tipo misto: "... plusieurs des espèces de ces régions présentent des caractères inhabituels pour les Dadoxylon. En particulier les ponctuations de la paroi radiale des trachéides peuvent en divers cas s'écarter de la disposition araucarienne classique. Ces éléments se trouvent assez souvent répartis en paires, espacées, de ponctuations opposées on en amas, distants les uns des autres, de ponctuations rapprochées ou accolées (groupes étoilés ou clusters)". E acrescenta: "Au contraire elles se rapprochent très nettement de celles que présentent certaines Coniférales mesozoiques à structure généralisée". Esta estrutura lembra muito as do Permo-Carbonífero do Hemisfério Sul. "Ainsi, d'une façon générale, les Dadoxylon austraux paraissent plus/avancés quant à l'évolution structurale, que leurs contemporains de l'hémisphère nord chez lesquels une disposition araucarienne des ponctuations radiales des trachéides/est la règle".

Nossa espécie apresenta também raios lenhosos bastante altos, que parecem resultar da reunião de dois ou três pequenos raios. Este fenômeno é freqüentemente observado em. certos gêneros de Ángiospermas Dicotiledôneas (raios articulados - Boureau, 1957, p. 586). É igualmente uma feição esporádica em algumas espécies de Gimnospermas atuais (Greguss, 1955) e em particular em Taxus baccata (Klinken, 1914) in Boureau, 1956; 373-374. Em geral, este caráter aparece progressivamente ao curso da ontogenia do vegetal. Porém a madeira recolhida em Bagé possui os raios articulados com 3 a 25 células de altura, desde os primeiros elementos do xilema situados junto à medula.

CONCLUSÕES GERAIS A Formação Irati do Afloramento Valente, Rio Grande do Sul, revelou a presença de numerosas estruturas lenhosas, com medula preservada ou não, pertencentes a diversos grupos vegetais. $O$ espécime descoberto nos folhelhos sílticos do Irati e descrito neste trabalho encontra-se associado ao gênero Polisolenoxylon (Gimnosperma) e a um pequeno fragmento lenhoso proveniente de uma porção de raízes de $P s a$ ronius ou Tietea (Filicopsida).

Este estudo nos permitiu evidenciar um plano anatômico original, porém apresentanto várias características freqüentemente encontradas entre as madeiras permo-carboníferas do Gondwana. Em verdade foram observados caracteres primitivos (alguns maciços lenhosos primários, com diferenciação centrípeta e centrífuga, dispersos ao redor de uma grande medula), associados à presença de fibras traqueídeos verticais guarnecidas de pontuações areoladas, principalmente do tipo araucarióide, algumas vezes arredondadas e espaçadas, como mostram certas ilustrações de Protopináceas mesozóicas. Este tipo de madeira secundạ́ria não é raro nos tẹritórios gondwânicos da América do Sul, da Antártica, da África do Sul, da Índia e da Austrália. Duas hipóteses podem ser então mencionadas quanto ao mesmo: uma, que corresponde a estruturas pertencentes a uma entidade 
sistemática, e outra, que corresponde a um estádio de evolução intermediário entre as formas araucarianas antigas e as madeiras abietineanas mais recentes, aparecendo precocemente no Hemisfério Sul. Ambas as hipóteses foram formuladas por vários paleobotânicos e, em particular, por Grambast (1960) para o grupo das Protopináceas. O mesmo autor mencionou igualmente a presença de pontuações do tipo "misto" para algumas madeiras do Hemisfério Sul, vinculando-as a estímulos climáticos diferenciados (zonas de crescimento). A porcentagem de pontuações espaçadas e arredondadas é entretanto muito fraca $(8 \%)$ em Bageopitys articulata n. gen., n. sp. e isso está certamente relacionado com a diferenciação centrípeta e centrífuga do xilema primário.

\section{BIBLIOGRAFIA}

BOUREAU, E. - 1956 - Ánatomie végétale. Paris, P. U. France Ed. 2: 333-524, Figs. 177-286, Est. VII-XII

BOUREAU, E. - 1957 - Anatomie végétale. Paris, P. U. France Ed. 3: 525-752, Figs. 287-369, Est. XIII-XXIII

FIGUEIREDO FILHO, P. M. de - 1972 - A faciologia do Grupo Passa Dois no Rio Grande do Sul. Rev. bras. Geociênc. 2(4): 216-235, Figs. 1-5, Fot. 1-5

GRAMBAST, L. - 1960 - Étude d'un Dadoxylon permian du Congo belga e remarques sur les Dadoxylon permo-carbonifères des territoires à flore de Gondwana. Ann. Mus. roy., Congo belge, Tervuren, in $8 .^{\circ}$, Sc. géol. 30: 22 pp., Figs. 1-3, Est. I-III

GREGUSS, P. - 1955 - Identification of living Gymnosperms on the Basis of Xylotomy. Akadémiai Kiadó, Budapest: 263 pp., Est. 1-350

JAPIASSU, A. M.S. - 1970 - Contribuição à Paleontologia da Formação Morro Pelado, Estado de Santa Gatarina, Brasil: Dadoxylon duartei n. sp. An. Acad. bras. Giênc. 42(3): 493-500, Figs. $1-4$, Est. I-II

KRAÜSEL, R. - 1960 - Zbl. Geol. Palaeont. 2: 586 pp., 1959

KRAÜSEL, R. e DOLIANITI, E. - 1958 - Gymnospermenhölzer aus dem Palaeozoikum brasiliens. Palaeontographica, Stuttgart, 104b (4-6): 115-137, Est. 16-26, Tabs. 1-7

KRAÜSEL, R., MAITHY, P. K. e MAHESHWARI, H. K. - 1962 - Gymnospermous woods with primary structures from Gondwana rocks - A review. Palaeobotanist, Lucknow, 10(1-2): 97-107, Figs. 1-25, 1961

LEPEKHINA, V. G. - 1972 - Woods of Palaeozoic pycnoxylic Gymnosperms. Palacontographica, Stuttgart, 138B(1-4): 44-106, Est. 16-30

MAHESHWARI, H. K. - 1972 - Permian wood from Antarctica and revision of some lower Gondwana wood Taxa. Palaeontographica, Stuttgart, 138B(1-4): 1-43, Est. 1-15

RAU, W. - 1933 - Cedroxylon canoense, una madera fóssil nueva del Rio Grande do Sul. Rev. Sudam. Bot., Montevideo, 1(3): 65-68, Figs. 1-3

RAU, W. - 1935 - Dadoxylon (Aratcarioxylon) butiense, n. sp. - Uma contribuição ao desenvolvimento da estrutura das Coníferas paleozóicas do Rio Grande do Sul. Bol. Soc. Eng. Rio Grande do Sul, Porto Alegre, 12: 11 pp., Figs. 1-11

SCOTT, D. H. - 1919 - On the fertile shoots of Mesoxylon and an allied Genus. Ann. Bot., London, 33: 1-21, Figs. 1-3, est. I-III

SCOTT, D. H. e MAESLEN, A. J. - 1910 - On Mesoxylon, a new genus of Cordaitales. - Preliminary Note. Ann, Bot., London, 24: 236-239

WALTON, J. $-1925-$ On some South African fossil woods. Ann. S. Afr. Mus., Capetown 22, Part. 1: 1-26, est. I-III 